\title{
Universal-Composite Adjustable Machine-Tool Attachments
}

\author{
V. E. Karpus' and V. A. Ivanov \\ Khar'kov Polytechnic Institute, Ukraine
}

\begin{abstract}
The basic requirements on positioning attachments in numerically controlled metal-cutting machine tools are considered. Existing adjustable, composite, and special attachments are analyzed. A new system of universal-composite adjustable attachments is proposed. The structure and characteristics of its components are outlined. As an example, an automatically adjustable universal attachment is developed for the machining of stepped shafts on numerically controlled milling and boring machines.
\end{abstract}

DOI: $10.3103 / \mathrm{S} 1068798 \mathrm{X} 08110105$

In manufacturing, characterized by unstable product ranges and output levels, rational selection of the technological equipment is a primary consideration in machining parts on numerically controlled machine tools. Of particular importance are positioning attachments, which must satisfy the following requirements:

sufficient flexibility for the machining of parts within the limitations of the machine tool;

specified accuracy of machining;

mechanized or automated adjustment on switching to a new product;

rigidity of the components and subassemblies of the attachment, so as to withstand considerable cutting forces and permit maximum utilization of the equipment's capacity;

an adequate tool complement, so as to machine the maximum number of surfaces in a single setup;

standardization of the parts and subassemblies of the attachment, for reasons of affordability;

high reliability of the attachment and its components;

economic efficiency.

Flexible and special attachments are used for the basing and attachment of blanks in metal-cutting machine tools. Flexible attachments may be adjusted with change in the product range. They may be divided into adjustable and composite attachments. Adjustable attachments include universal nontunable attachments (UNA), specialized nontunable attachments, universal tunable attachments (UTA), specialized tunable attachments (STA), specialized tunable attachments for numerically controlled machine tools (STA-NC), and automatically adjustable attachments (AAA). Composite attachments include universal-composite attachments (UCA), universal-composite attachments for numerically controlled machine tools (UCA-NC), universal-composite mechanized attachments (UCMA), universal-composite adjustable equipment (UCAE), and assembly-disassembly attachments (ADA).
Several stages may be distinguished in the development of machine-tool attachments. At the beginning of the twentieth century, special attachments appeared. In the mid-1920s, for the sake of greater flexibility, universal nontunable attachments were developed. Universal tunable attachments and specialized tunable attachments were widely adopted in the 1930s and 1940s, respectively. In the 1950s, under the leadership of Kuznetsov and Ponomarev, universal-composite attachments were developed. In the $1960 \mathrm{~s}$, under the leadership of Filatov and Leonov, assembly-disassembly attachments were introduced [1]. In the 1970s, universal-composite adjustable equipment was developed; it represented a considerable advance over existing composite attachments.

Each attachment system has particular benefits and ensures a certain level of product flexibility, as well as the required machining productivity and accuracy. Thus, special attachments have no flexibility, but ensure high productivity and accuracy thanks to their structural rigidity. They are intended for a single technological operation and may rationally be used in mass production if adjustable attachments cannot be used for blank placement.

Adjustable attachments are very flexible, since they may readily be switched from one product to another. Regulation simply involves the clamping and supporting elements (nontunable attachments) or replacement of the adjustable settings (tunable attachments), which is considerably more rapid. On average, the cost of replacing the adjustable settings is $4-5$ times less than the cost of a new special attachment. As a rule, 7-10 different settings may be used with a single basic unit. Hence, by switching the settings in the adjustable attachment, up to ten special attachments for the machining of different parts may be replaced. The use of universal and specialized tunable attachments allows precision of class $8-9$ to be obtained in surface machining $[2,3]$. The classification of adjustable attachments is summarized in Fig. 1. 


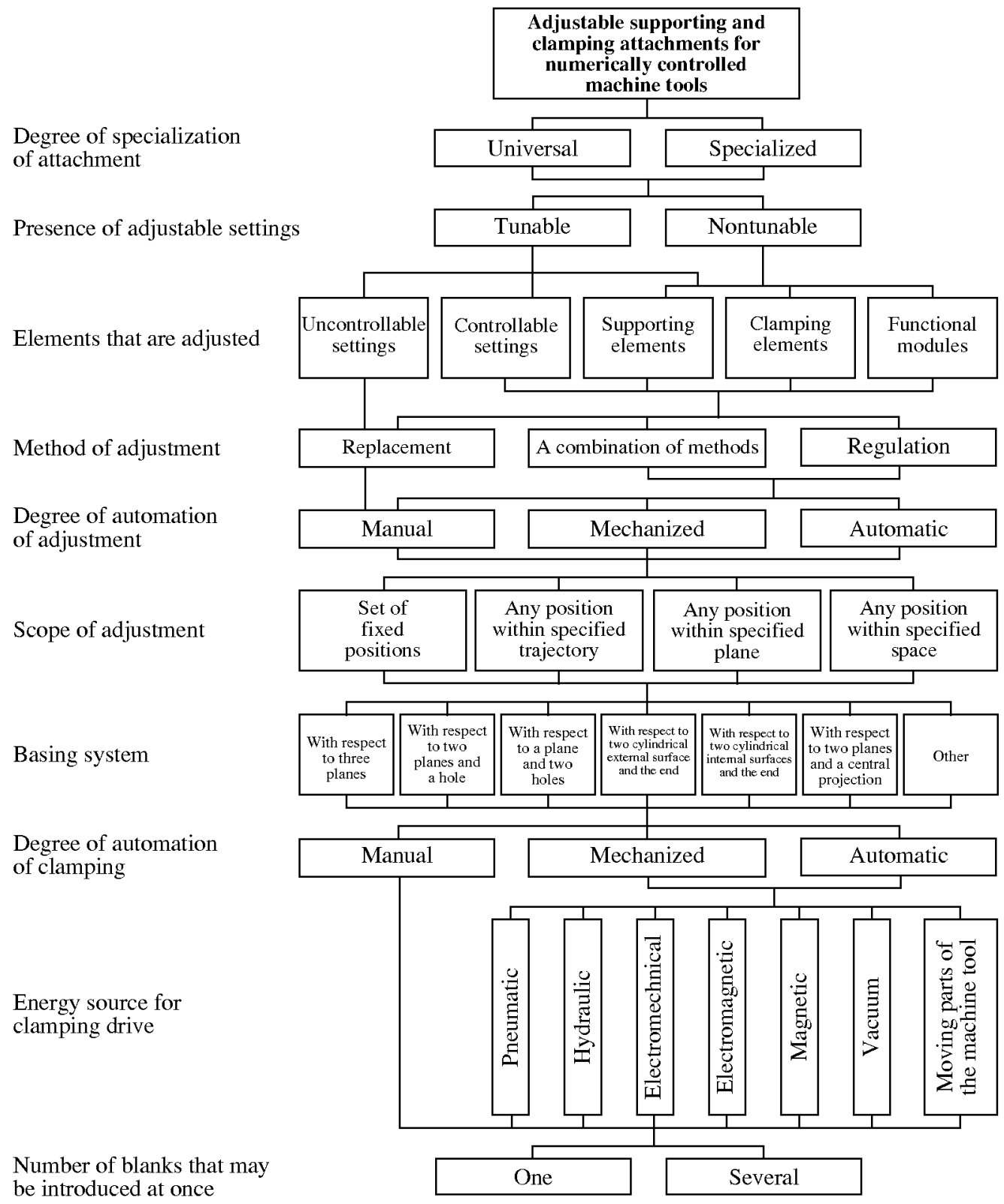

Fig. 1. Classification of adjustable supporting and clamping attachments.

Composite attachments are universal for the manufacture of a particular set of elements. However, after the assembly of a certain configuration, the attachment is specialized. This explains their poor flexibility relative to adjustable attachments. The use of composite attachments follows this pattern: assembly, operation, disassembly, assembly of a new structure, and so on. Depending on the skill of the assembly staff and the equipment available, reequipping the attachment for machining a new part takes $0.5-4 \mathrm{~h}$ [4].

The adjustment of attachments in composite-attachment systems entails reconfiguring their components and switching the clamping and supporting elements within the housing. The replacement of adjustable set- tings is only possible in universal or specialized tunable attachments. The position of the clamping and supporting elements may be regulated, and the adjustable settings may be modified. Regulating the position of the clamping and supporting elements permits the application of the retaining force to the required point. Manual, mechanized, or automatic adjustment of the attachments is possible. Automated adjustment within a numerical control system is most effective.

The preliminary capital expenditure on equipment is often the decisive factor in selecting the attachment system. The high cost and extensive components of composite attachment systems call for large preliminary capital expenditures. For example, the cost of the USP- 
Technical characteristics of attachments

\begin{tabular}{|c|c|c|c|c|c|c|c|c|c|c|c|}
\hline \multirow[b]{2}{*}{ Characteristic } & \multicolumn{5}{|c|}{ Composite attachments } & \multicolumn{5}{|c|}{ Adjustable attachments } & \multirow{2}{*}{$\begin{array}{c}\begin{array}{c}\text { Universal-composite } \\
\text { adjustable attachment }\end{array} \\
\text { UCAA }\end{array}$} \\
\hline & 巳્ర & 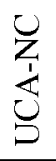 & $\underset{⿱ 乛}{\stackrel{S}{S}}$ & $\sum_{S}^{2}$ & 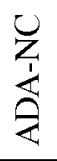 & $\overleftrightarrow{\zeta}$ & 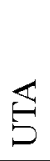 & 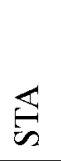 & $\underset{⿱}{\sum_{n}}$ & $\sum$ & \\
\hline \multicolumn{12}{|c|}{ Method of adjustment } \\
\hline Reconfiguration of components & + & + & + & + & + & & & & & & \\
\hline $\begin{array}{l}\text { Replacement of adjustable set- } \\
\text { tings }\end{array}$ & & & & & & & + & + & + & & + \\
\hline Regulation of setting positions & & & & & & & & & & & + \\
\hline $\begin{array}{l}\text { Regulation of positions of sup- } \\
\text { porting and clamping elements }\end{array}$ & & & + & & + & + & & + & + & + & + \\
\hline $\begin{array}{l}\text { Regulation of clamping-module } \\
\text { position }\end{array}$ & & & & & & & & & & & + \\
\hline \multicolumn{12}{|c|}{ Degree of automation of adjustment process } \\
\hline Manual & + & + & + & + & + & + & + & + & + & & \\
\hline Mechanized & & & & & & + & & + & & & + \\
\hline Automatic & & & & & & & & & & + & + \\
\hline \multicolumn{12}{|c|}{ Degree of automation of clamping process } \\
\hline Manual & + & & & & + & + & & & & & \\
\hline Mechanized & & + & + & + & + & + & + & + & + & & + \\
\hline Automatic & & & & & & & & & & + & + \\
\hline \multicolumn{12}{|c|}{ Range of adjustment of supporting and clamping elements } \\
\hline Set of fixed positions & + & + & + & + & + & & & & & & \\
\hline $\begin{array}{l}\text { Any position within specified } \\
\text { trajectory }\end{array}$ & + & + & + & & + & + & + & + & + & + & + \\
\hline $\begin{array}{l}\text { Any position within specified } \\
\text { plane }\end{array}$ & & & & & & + & & & & + & + \\
\hline $\begin{array}{l}\text { Any position within specified } \\
\text { space }\end{array}$ & & & & & & & & & & + & + \\
\hline \multicolumn{12}{|c|}{ Characteristics of blanks that may be introduced } \\
\hline $\begin{array}{l}\text { Blanks of similar shape, with } \\
\text { identical basing configuration }\end{array}$ & & & & & & + & + & + & + & + & + \\
\hline $\begin{array}{l}\text { Blanks of similar shape, with } \\
\text { different basing configurations }\end{array}$ & & & & & & & + & & & & + \\
\hline $\begin{array}{l}\text { Any blanks within the limits of } \\
\text { the technical characteristics }\end{array}$ & + & + & + & + & + & & & & & & \\
\hline
\end{tabular}

8 set is around 2 million rub. Such expenditures are out of reach of most manufacturing enterprises, especially smaller enterprises.

In these circumstances, it is preferable to use adjustable attachments. However, with current machine-tool capabilities and working-table dimensions, their design and manufacture may not be justified, since blanks of moderate size are most often machined. Therefore, it is expedient to have dimensional series of adjustable attachments for blanks of different types.
Experience with composite attachments suggests that it is more rational to base them on standardized components and subassemblies. Thus, it is expedient to develop an attachment system that combines the benefits of composite and adjustable attachments: a system of universal-composite adjustable attachments (UCAA), as shown in Fig. 2.

The base plate of the universal-composite adjustable attachment is an analog of the hydraulic modules of composite attachments with built-in hydraulic cylin- 


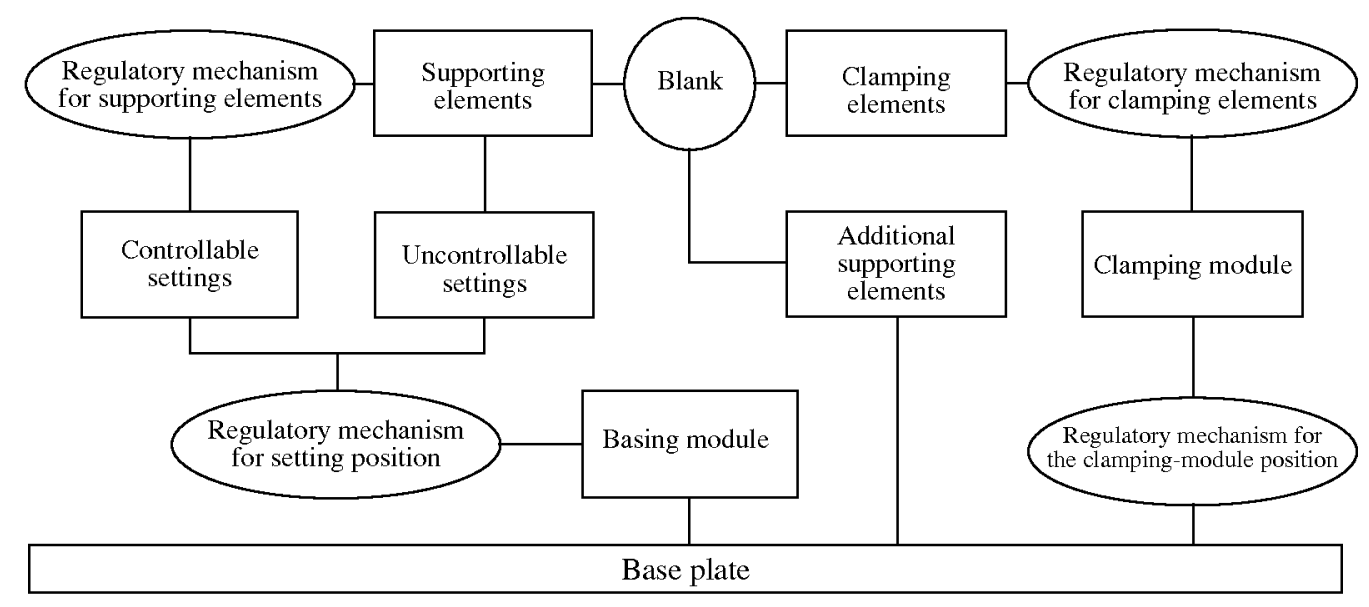

Fig. 2. Structure of universal-composite adjustable attachment.

ders and oil-supply lines. The basic components and subassemblies are mounted on the base plate.

The basing module is a composite unit mounted on the base plate. It is responsible for basing the blank. Depending on the range of parts being machined, various adjustable settings are established for the basing module; they may be adjusted by means of the corresponding regulatory mechanism. For example, the settings over the length of the basing module may be positioned by means of a linear motor, which ensures high positional accuracy throughout the working life of the attachment, on account of the lack of friction, the simple design, and operational reliability.

As a rule, the adjustable settings, which may or may not be regulated, are established at one surface of the basing module. On the basis of the unregulated settings, blanks of different size but similar configuration may be attached within a common basing setup. For example, the unregulated settings for basing solids of revolution machined by boring and milling correspond to standardized prisms, such that the blanks are established at a cylindrical surface (diameter 5-150 mm). Regulated settings permit the attachment of the required set of parts, since they permit regulation of the supporting elements within the specified technical characteristics.

The supporting elements of the attachment maintain the theoretical basing system for the blank and ensure sufficient stability in machining. Note that, in installing the blank on its unmachined surfaces, it is expedient to use supporting elements with a limited supporting surface. When the base surfaces of the blank have been machined, the supporting surface increases.

The supporting elements may be adjusted by means of elementary regulatory mechanisms (for example, adjustable screw supports) or by means of some combination of gear transmissions and rack, lever, cam, or eccentric mechanisms.
When introducing long shafts in which the surfaces to be machined are far apart, supplementary supporting elements ensure the necessary rigidity in machining. The supplementary supporting elements take the form of adjustable supports.

The clamping element is a part or group of parts in direct contact with the blank and presses it against the supporting element, ensuring that the position of the blank is constant during machining. The proposed attachment uses a range of standardized clamping elements, permitting rapid removal of the part and introduction of the new blank in the attachment. Such elements may include arms, clamps, levers, cams, and pins. The number of clamping elements will be selected on the basis of the shape and size of the blank to be machined. Regulation of the clamping element by means of screw, wedge, cam, lever, eccentric, and other mechanisms is possible.

The clamping module is a composite unit consisting of parts that together create the force transmitted to the clamping element. The selection of the clamp drive is based on the required force and speed and the size of the attachment. Manual, mechanized, or automated regulation of the drive is possible. Hydraulic, pneumatic, electromechanical, electromagnetic, magnetic, vacuum, and other drives may be used. The position of the clamping module relative to the base plate may be changed by means of a regulatory mechanism. For example, a linear motor permits adjustment of the point of application of the clamping force overt the whole length of the blank according to the machine tool's numerical control system.

The table presents comparative data on various attachment systems.

As an example, consider the basing of a stepped shaft at the external cylindrical surface in universal, mechanized, and automated attachments. This is the most common basing systems for shafts machined on numerically controlled drilling and milling machines. 


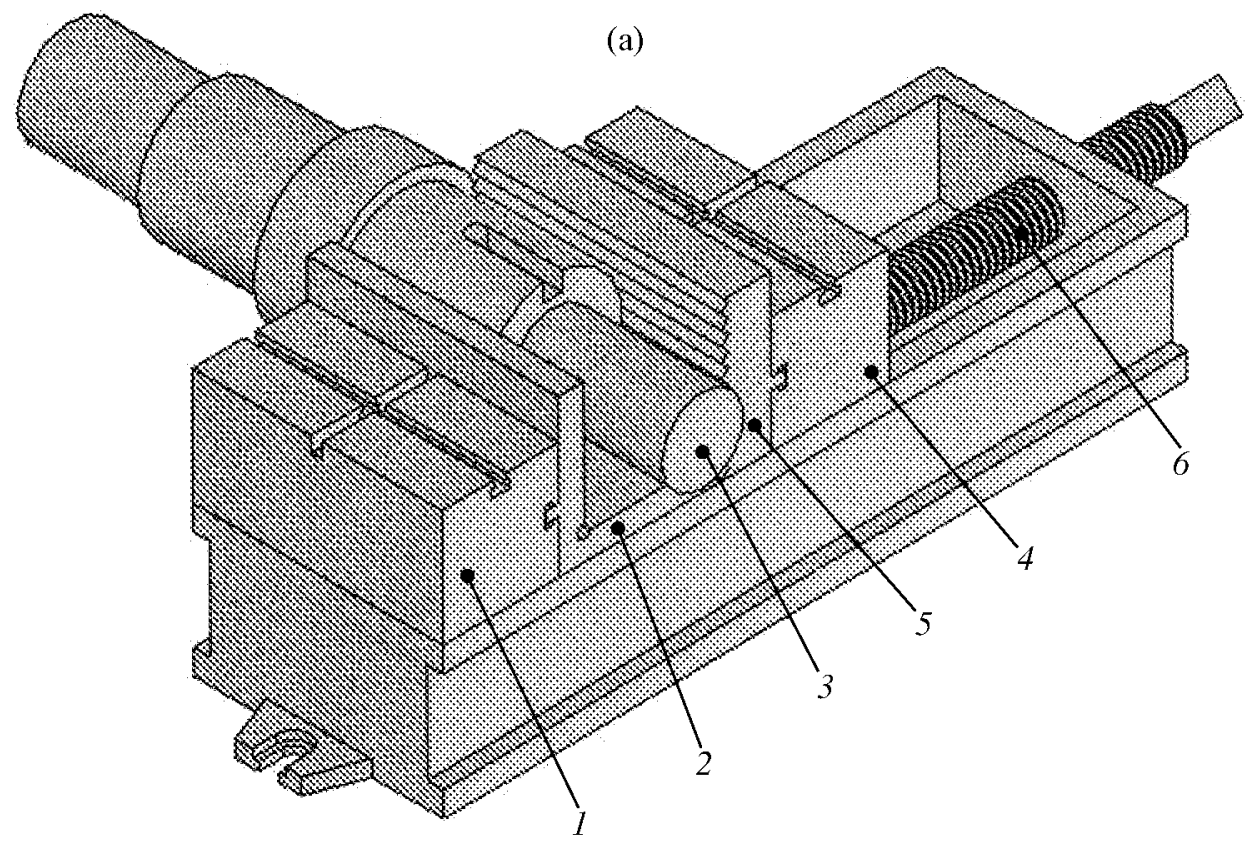

(b)

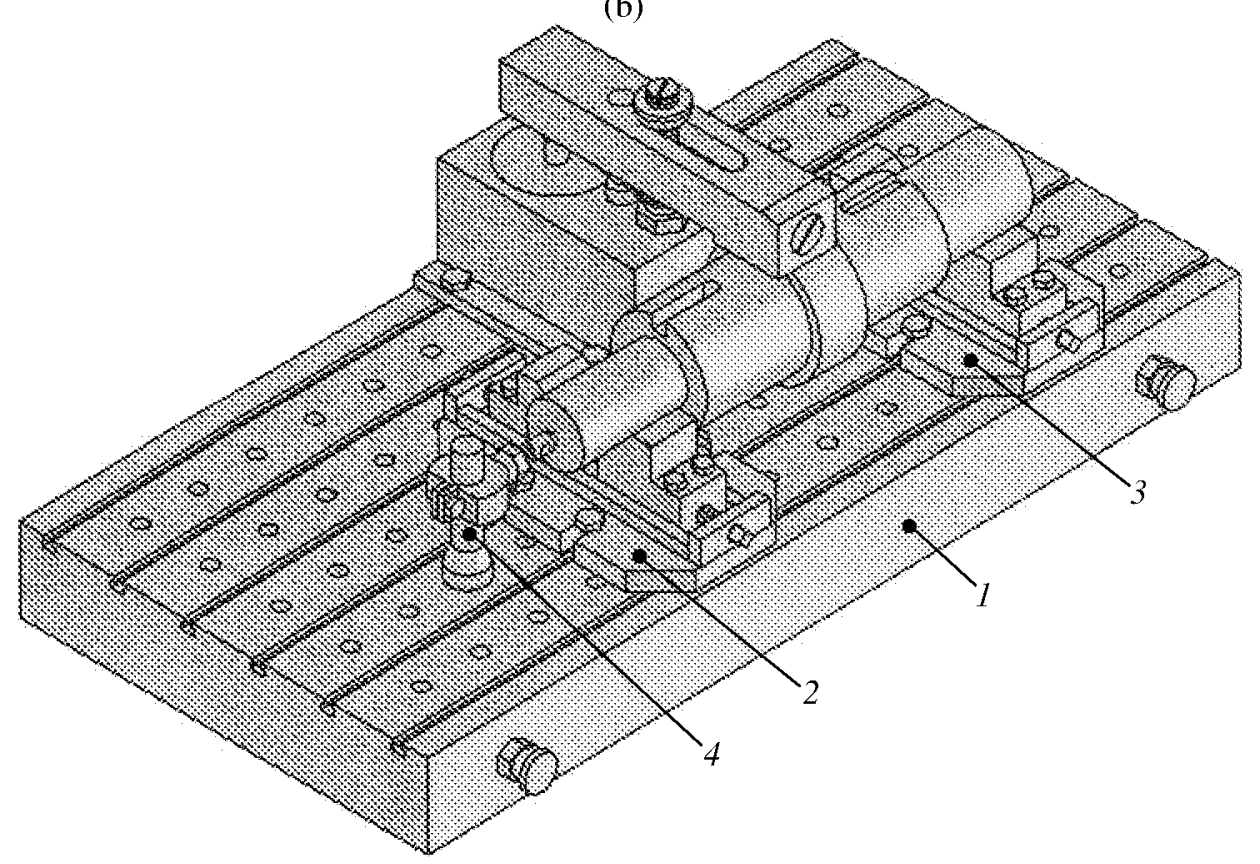

Fig. 3. Installation of stepped shaft for slot milling: (a) in universal clamp; (b) in assembly-disassembly attachment.

When the blank is introduced in a universal clamp (Fig. 3a) for milling a slot, L-shaped plate 2 is pressed against immobile block 1 . The neck of the blank 3 is placed on plate 2 . The blank is held in place by moving block 4 with adjustable setting 5 , using screw 6 . Thus, the necessary rigidity of the blank is ensured during slot milling. The blank must be moved if several slots are to be milled. The machine-tool operator attaches and removed the blank.
On introducing the blank in an assembly-disassembly attachment (Fig. 3b), it is based at the external cylindrical surfaces and at the end. Controllable prisms 2 and 3 and support 4 are placed on plate 1 , which is attached to the machine tool's table. The half-prisms are regulated by a screw with left and right threads, which permits simultaneous adjustment of both halfprisms to the necessary basic blank diameter, aligning the axes of the prisms and the blank. To change the dis- 

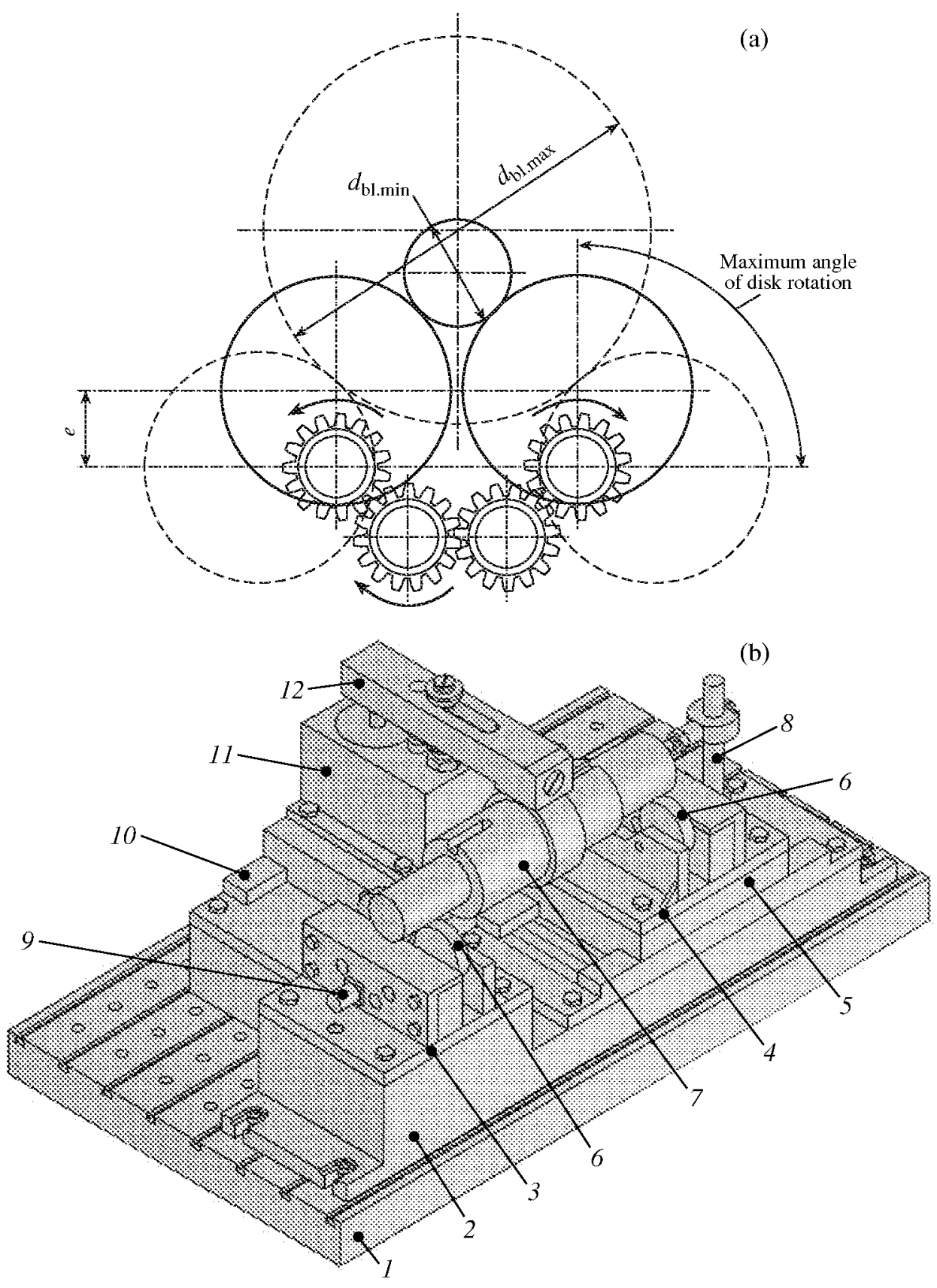

Fig. 4. Universal-composite adjustable attachment: (a) regulatory mechanism for supporting elements; (b) configuration of attachment.

tance between prisms 2 and 3 , one of the prisms must be reinstalled. A hydraulic cylinder serves as the mechanized clamp drive. On switching to different products, the operators must reconfigure the attachment. The benefit of this attachment over a universal clamp is the possibility of machining several surfaces without reinstalling the blank. In addition, a mechanized drive is used to clamp the blanks.
Formulation of the attachment from components of the new system of universal-composite adjustable attachments is proposed, on the basis of an automatically adjustable basing prism (Fig. 4a). The supporting elements take the form of disks, whose axis of rotation is shifted relative to the disk axis by eccentricity $e$. When the gear system goes into operation, the supporting disks turn simultaneously in different directions 
through a specified angle, corresponding to the diameter of the blank, in the range $d_{\mathrm{bl.min}}-d_{\mathrm{bl.max}}$. The maximum angle of rotation of the supporting disks is $90^{\circ}$. In basing stepped shafts at surfaces with a diameter of $25-$ $100 \mathrm{~mm}$, the diameter of the supporting disks must be $60 \mathrm{~mm}$.

Base plate 1 , which supports the basing prism (Fig. 4b), is attached to the machine tool's working table. Then, basing module 2 is introduced on the base plate, and adjustable settings 3 and 4 are installed. Adjustable setting 3 is rigidly fixed to the basing module; adjustable setting 4 is attached to carriage 5 of the linear motor, so that the distance between the supporting disks 6 may be adjusted and the necessary rigidity of blank 7 may be ensured during machining. Blank 7 , which is a stepped shaft, is installed with its base surfaces at supporting disks 6 , with a stop at the end. Stop 8 may be regulated over the height and the length of the controllable support. The machine tool's numerical control system sends commands to step motors 9, which turn the supporting disks through the required angle, corresponding to the basing diameter of the blank. The signals are transmitted separately to the step motors; this permits adjustment of the supporting disks to different diameters. Linear motor 10 changes the longitudinal position of clamp module 11. The blank is fixed in place by clamp 12, which ensures unobstructed removal of the machined part and insertion of a new blank. Clamping and unclamping of the blank is automatic, as is adjustment of the attachment for a different product.
The benefit of the proposed design utilizing basing prisms is that the supporting disks may be automatically adjusted to the required diameter of the blank and the distance between the adjustable settings may be modified in accordance with the machine tool's numerical control problem. Moreover, the clamping force may be applied to any point of the blank.

Analysis of the proposed attachment, which is characterized by high levels of flexibility and automation, confirms that it is expedient to equip numerically controlled mass-production metal-cutting machine tools with a system of universal-composite adjustable attachments, which permit automatic adjustment for a new product, are highly flexible, and require minimal equipment costs.

\section{REFERENCES}

1. Murashov, A.M., Agregatirovanie stanochnykh prisposoblenii (Assembling Machine-Tool Attachments), Moscow: Izd. Standartov, Mer i Izmeritel'nykh Priborov, 1966.

2. Cherpakov, B.I., Tekhnologicheskaya osnastka (Technological Equipment), Moscow: Akademiya, 2003.

3. Zholtkevich, N.D., Movshovich, I.Ya., Kobzev, A.S., et al., Obratimaya tekhnologicheskaya osnastka dlya GPS (Reversible Technological Equipment for Group Production Systems), Kiev: Tekhnika, 1992.

4. Boguslaev, V.A., Lekhovitser, V.A., and Smirnov, A.S., Stanochnye prisposobleniya (Machine-Tool Attachments), Zaporozh'e: OAO Motor Sich, 2000. 